\title{
Community dentistry: developmental discussion approach
}

\author{
EMERSON Robinson \\ Department of Community Dentistry, School of Dentistry, The University of Michigan, \\ Ann Arbor, Michigan, U.S.A.
}

\begin{abstract}
ABSIRACT - In 1960, BlAckERBY asked the question "Why not a department of social dentistry?". Since that time most of the dental schools in the United States have made some attempt at establishing such a department. Various names were given to these departments, but the one that appears to be in the forefront is the Department of Community Dentistry. Since that time each school with such a department has strived to develop various innovative methods of teaching community dentistry to its students. When the amount of time is taken into consideration, unlike the biological and clinical sciences, time allotted to community dentistry is minimal. However, at The University of Michigan students spend 232 hours in community dentistry, which necessitates development of creative teaching techniques to maintain their interest. This paper discusses one such technique which has proven to be successful over the past 3 years. Emphasis is placed on utilizing a modified method of the developmental discussion approach in teaching a course in community dentistry to 3rd-year dental students.
\end{abstract}

(Accepted for publication 3 July 1977)

Designing a course in community dentistry that is both relevant and meaningful to the dental student is a challenging task. When one observes dental school programs, it becomes obvious that comparable differences exist in the design of teaching programs in community dentistry. Finding effective ways to teach community dentistry courses is a source of great interest to educators in this area. Which method of course design, i.c. lectures, seminar, experimental learning, lecture and seminar combinations, or lectures and guest speakers, provides the student with the most meaningful learning cxperience?

It is not enough to teach for cognitive knowledge. It seems important for professors to concern themselves with all the competencies to be developed by students and ways of teaching to facilitate the development of these competencies. Obviously, knowledge plays a vital rolc in the teaching process, yet it must not be viewed as the only product of one's teaching efforts. As attention is focused upon the total competencies needed in performing the numerous tasks of a dentist, it is possible for us to teach for knowledge. If, however, we teach only for knowledge, we limit our effectiveness. We must recognize the interrelationship between the process of learning and the process of teaching.

Knowledge acquired by the student becomes highly important to teachers in any professional school. Professors of dentistry need to make sure that particular elements of knowledge essential to becoming a good and competent dentist are disseminated. Probably one of the questions that is brought to mind is: how does one teach for knowlcdge? What is the teaching-learning process that facilitates the acquisition of knowledge? Learning is more than memorizing. For example, one can memorize and draw the "Kreb's cycle", yet have no facility in verbalizing the logic underlying such a formula. Mere memorization of facts does not insure 
the acquisition of functional knowledge. A passing grade on an examination is not necessarily indicative of having acquired knowledge.

Teaching is effective only if it promotes the inner motivation to learn. Generally, when students enter dental school, they bring with them their patterns of learning and motivation. Unfortunately, there are repeated indications that by the time they approach graduation, some of the positive motivations and ideals which they had as freshmen are lost. One strong force in motivation to learning is identification with the teacher. A teaching method which allows for this type of interaction and strengthens the student-teacher relationship is the group discussion method.

Learning, like growth, can essentially be a pleasant experience, but a student's enjoyment of learning can be promoted or inhibited by the manner in which the course is presented. The group discussion also provides for clarification and progressive orientation of the topics covered during the sessions.

In looking at the various methods that have been and are presently being used to teach some community dentistry courses at The University of Michigan, it has been observed that students respond more positively to the group discussion approach than to lectures, lectures and guest speakers, or a combination of lectures and seminars. After recognizing the importance of this method as perceived by both the department and students, efforts were made to develop a highly organized group discussion approach in teaching community dentistry to junior dental students.

The term "developmental discussion" was coined in 1952 by N. R. F. MAIER ${ }^{1}$ to describe a problemsolving discussion technique in which the teacher breaks problems into parts so that all group members are working on the same part of the problem simultancously. Utilizing this basic concept, instead of problem-solving, the course is designed to have students work on a task in a group situation.

An early step in developmental discussion is to obtain information relevant to the topic for discussion. Such information in this teaching approach is provided by a compendium of the reading assignments and the topic to be discussed in each session. Topics for discussion are constantly changing. Consequently, attempts are made to maintain current information from year to year. Like other discussion methods, developmental discussion implies active participation of all members in the group. Participation is directed to a definite goal related to the assigned task that is given to the student. However, this does not imply that the assigned task is designed to manipulate the students into following steps to reach a predetermined solution. In fact, most of the designed tasks are not soluble by the group, but rather, discussions result in formulations of relationships, applications, and analyses of facts and materials related to the assigned tasks.

The discussion groups cover the same academic material as would have been presented in lectures through assigned readings. The discussion groups, instead of being lectured to, conduct exercises designed to amplify the text material. Each of the discussion group leaders has a standardized format for conducting the seminars and a list of pertinent points to be brought up during the discussions.

The course strives to help the student gain insight into the topic that is discussed. Insight enables the learner to understand what has to be achieved and to invent ways of achicving it by making proper responses.

Group discussion is a process of cooperative thinking which leads the students into pooling their experiences, knowledge, and judgment, with cach giving to the others an equal opportunity to expose and support their points of view, and with a determination not to defend an established policy but to seek openmindedly for the best available - all aiming toward the final formulation and adoption of the most practical solution.

Particularly for this type of classroom situation, four guiding rules aid in making the discussion successful:

1. The task should be stimulating and uncomplicated.

2. The task should be so worded as to suggest no single answer.

3. The task must not require unavailable knowledge, unusual experiencc, or cxtensive rescarch.

4. The task should be sufficiently limited to permit profitable discussion within the allotted time.

This method has helped the staff and students discuss subject matter from a variety of viewpoints. The stimulation of interpersonal communication has allowed both student and instructor to rationalize and substantiate the relevancy for each segment of the course, which, prior to the implementation of the group discussion, was solely designed on the 
basis of the particular philosophy of an instructor. Although the ultimate responsibility for the direction which the discussions take is that of the instructor, the flexibility of this approach is such that it allows students to express their opinions and challenge those of others, including the instructor. Utilizing the developmental discussion approach has resulted in the following:

1. The students are not "apprehensive" in expressing the way they feel about the subject matter, as has been the case in the past.

2. The instructors, when participating, and students enter into discussions on common ground. This has resulted in a mutual respect since the student realizes that the determination is not one-sided.

3. Students have become more aware of the necessity to have knowledge of other aspects of dentistry, rather than only that which relates to the clinical.

\section{COURSE PROCEIJURES}

Considering that the class size (150 students) and the number of instructors in the department represent a less than ideal ratio for adequate discussions to take place, it was necessary to divide the class into two sections of 75 students. The following procedures list the steps necessary for implementing the group discussions:

1. The class of 150 students is divided into 16 groups of 9-10 members each.

2. One-half of the class, composed of eight groups mecting with eight instructors, is involved in the discussions during one of each class period which meets for 1 hour, 2 days per week.

3. All students receive handouts concening the topic to be discussed, including the related assigned readings and objectives of the seminar, prior to meeting with their assigned groups.

4. A task related to the topic and readings is given to the student when the group meets.

5. The course is scheduled for 15 weeks and consists of 30 sessions. Each student meets 14 times with his discussion group. Within the 15 -week period, one session is for the course instruction, and the other is for the mid-term examination.

It is the students' responsibility to read the information pertaining to the topic for discussion prior to meeting with their respective groups. Although the readings are not absolutely critical, they do facil- itate student participation in the groups from a more intelligent point of vicw if the reading has taken place. Familiarization with the materials gives the student a broader foundation for participation and also lessens the probability of being uncomfortable during the group sessions. Most of the specific objectives of the course are designed to gain information that the student will be tested on, which serves as a motivation for reading the materials. The uniqueness of the developmental discussion approach is that the sessions are student-oriented, which allows them to express their knowledge and opinions about the subject being discussed and gives some direction to the discussion. Although the instructors remain somewhat passive during the discussions, they clarify student misinterpretation of information being discussed or explain points that appear to be unclear to the students. The first attempt at utilizing the seminar approach in teaching this class resulted in the focus being on the instructor, which on many occasions led to mini lectures. Realizing this brought about utilization of the developmental discussion approach.

Each session is based on a task that has to be worked on before a general discussion is undertaken with the entire group. Usually the discussion group is broken up into two or three smaller groups. Each small group is given a task related to the discussion topic which they work on for 20 to $30 \mathrm{~min}$, depending on the task. This small group approach insures that all students participate at this level. After the smaller groups complete their tasks, they come back together as one group and, through discussion of their assigned tasks, interact as a total group. Usually a spokesperson is selected by each small group to initiate the group discussions or present their position of a given task, with the members of the other small groups reacting and responding to their presentation.

\section{COURSE TOPICS}

The following topics are covered in the 14 group discussions:

1. The health care system

2. Dentistry: an integral part of the health care system

3. Dental manpower

4. Problems involving the dental health carc system 
5. Peer review and professional standards review organizations (PSRO's)*

6. Continuing education

7. Reciprocity

8. Consumerism in health care delivery

9. Denturism

10. National health insurance

11. Health maintenance organization

12. Expanded duties of dental auxiliaries

13. Prepaid dental care

14. Dentistry and its future

\section{TASK PROCEDURE}

A typical session is designed in the following manner: the student is given a handout pertaining to the topic for discussion prior to coming to class. The table of contents of the handout generally consists of:

\section{Objectives}

2. Student preparation

3. Information pertinent to the discussion

4. Article to be read

5. Discussion questions

This format gives the students a sequential approach in preparing for the task that is to take place in the group. An example of one of the tasks that is designed for the discussion group is as follows:

\section{SEMINAR X - NATIONAL HEALTH INSURANCE Task}

Given that the United States is the only major industrial nation without a comprehensive national health insurance plan, the probability of eventually having one is not remote. Assuming that one of the five plans presented in the assigned readings, "National health insurance - Which way to go?" will be implemented, select one of the plans that best meets the approval of your group using the live minimum consumer goals as criteria for this determination. Your group should prepare itself during this time to discuss its rationale for selecting one of the five plans based on the five minimum consumer goals.

Twenty-five minutes are allowed for working on the task in two subgroups, and $25 \mathrm{~min}$ are allowed for group presentations. During the preceding ses-

\footnotetext{
*PSRO's - The PSRO program was cstablished by Public Law 92-603, enacted by the Congress of the United States in 1972 as a series of amendments to the Social Security Act, to evaluate health care services provided under Social Security programs, primarily Medicare and Medicaid (fedcrally funded programs).
}

sion, students are asked to familiarize themselves with the five goals and make an individual selection of one of the plans prior to coming to class so as to facilitate discussion.

All of the handouts have general objectives for each topic related to the discussion. However, there are specific objectives related to the assigned readings in the syllabus received during the introductory period. The reading assignments basically serve two purposes:

1. To expose the students to information that will facilitate discussion within the group session.

2. To assess the students' progress in the course as it relates to reading the assigned readings.

\section{STUDENT EVALUATION}

Evaluation is based primarily on student participation. Because the designed tasks create an atmosphere for group participation, very few students do not participate or contribute to the task which they are assigned. When this does happen, the instructor intercedes and tries to assist the student in becoming involved with the group. Usually, it is a person who is reluctant to speak in groups.

The student's grade is determined by:

1. Participation in discussion groups $(50 \%)$. Participation is based on the following rating scale for each group discussion:

$2.5=$ Poor - Shows no evidence of knowledge of the assigned reading.

5 = Fair - Shows some knowledge of the assigned readings, but lacks conciseness and clarity.

$7.5=$ Good - Shows knowledge of the assigned readings with conciseness and clarity.

This simplified method of grading is used to minimize any extreme variations in grading by the eight different instructors. Prior to using this simplified method, a more elaborate type of grading system was used and it created great differences in the grading by the instructors. Utilizing this simplified method, there has been no significant variation between the eight instructors when the grades are reviewed at the end of the semester.

2. Two written examinations ( $25 \%$ each).

The major learning objectives for this course are:

1. To obtain information from the dental litera- 
ture about several topics that currently relate to the profession and the practice of dentistry.

2. To practice the skills of interpersonal communication in a small group.

3. To clarify personal values and opinions regarding some topics of importance that affect the profession and practice of dentistry.

\section{COURSE EVALUATION}

Evaluation of the course is based on the above criteria through a questionnaire given to the students on the last day of class. In 1975, 146 students filled out the questionnaire and, rating the class on a scale of $1-5$ wherein 5 is lowest, the course value index was 2.51; in 1976 it was 2.4, and in 1977 it was 2.62. The instructors were also rated during this period and the value indices were $1.88,2,4$, and 1.88 , respectively.

The developmental discussion approach that is currently being used evolved to its present state over a period of 3 years. It is felt that past experience and student opinions justify maintaining this approach with possible minor modifications in the future.

Courses which teach the students how to perform clinical procedures tend to take precedence over others. Consequently, it is felt that it is necessary to utilize an educational method such as the devclopmental discussion approach in order to make the type of information presented in community dentistry classes more appealing to the dental student.

\section{REFERENCE}

1. McKracine, W. J.: Teaching tips: A guidebook for the beginning college teacher. 6th ed. D. C. Heath \& Co., Lexington, Mass. 1965, pp. 52-84.

Address:

Department of Community Dentistry

School of Dentistry

University of Michigan

Ann Arbor, Michigan 18109

U.S.A. 
This document is a scanned copy of a printed document. No warranty is given about the accuracy of the copy. Users should refer to the original published version of the material. 